\title{
Rating and assessment of the effectiveness of self-regulatory organizations in the field of engineering research
}

\author{
Elena Matys ${ }^{1 *}$, Natalia Meller ${ }^{1}$, Inna Nekrasova $^{1}$, and Christina Degtyareva ${ }^{1}$ \\ ${ }^{1}$ Tyumen Industrial University, 625000,38 St. Volodarsky, Tyumen, Russia
}

\begin{abstract}
Investment and construction activities are represented by a combination of a multitude of economic entities and economic relations between them. The Institute for Self-Regulation of Entrepreneurial and Professional Activities in Russia is innovative in terms of regulating market relations. However, the number of areas of activity that apply the principles of self-regulation is growing every year. There is a need to decide on the choice of a self-regulatory organization. The urgency of this professional community needs a system of self-regulatory organizations. The system of rating and evaluation of the effectiveness of a selfregulatory organization is necessary both for the participants in selfregulation and for the state. This is an obligatory condition for the interaction of the professional community with the authorities. This study allows to evaluate the quantitative and qualitative indicators that affect the overall efficiency of the activity and the rating of a self-regulatory organization.
\end{abstract}

\section{Introduction}

Companies that are engaged in all types of research activities related to the quality and safety of the construction of oil and gas production facilities should necessarily have an SRO permit for engineering research. The companies get such permit when they are included in self-regulatory organizations (SRO). A company that provides service for all types of engineering research must be authorized by an SRO, which ensures established rules and regulations. Obtaining a document is a guarantee of compliance with mandatory requirements.

Self-regulatory organizations have become an integral part of the entrepreneurial (professional) activity spheres of Russia. It will soon be 10 years since the moment when state licensing in construction was replaced by a self-regulatory system. Throughout the entire period of its existence, this system has been constantly modernized - new laws, bylaws and amendments to existing standards come into force annually [1].

The variety of different SROs in each region is due to the distribution of demand in a single field of activity between market players.

\footnotetext{
*Corresponding author: matyseg@tyuiu.ru
} 
Despite the uniform legislative base and extensive representation in the regions, all of them differ from each other:

- by industry;

- by composition and territorial coverage;

- by the features of an individual approach;

- by the internal requirements and standards.

The number of SROs in the Russian Federation by areas of entrepreneurial (professional) activity, as of January 1, 2018, is presented in Figure 1.

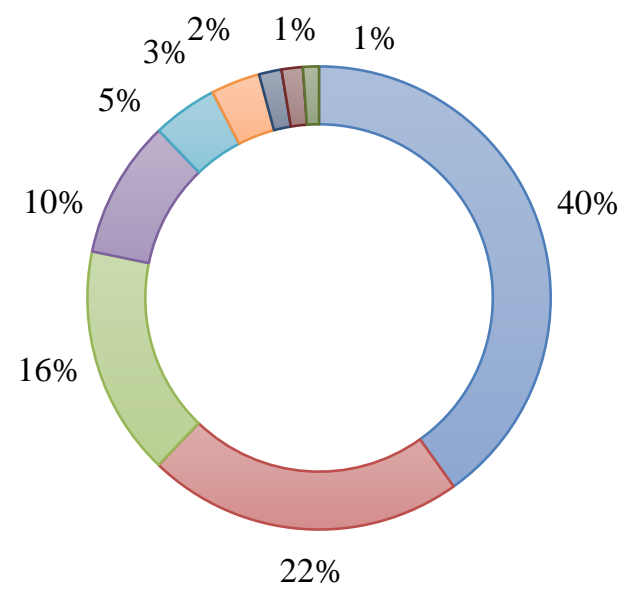

$\square$ sphere $1 \square$ sphere $2 \square$ sphere $3 \square$ sphere $4 \square$ sphere 5

$\square$ sphere $6 \square$ sphere $7 \square$ sphere $8 \square$ sphere 9

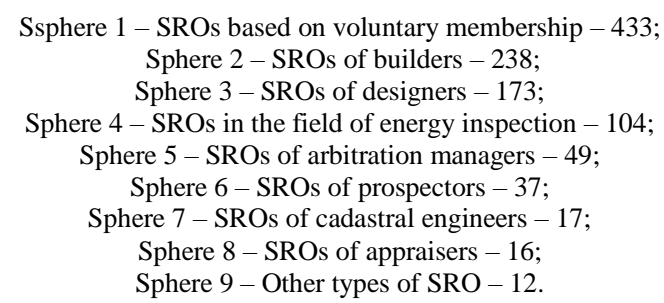

Fig. 1. The number of SROs in the Russian Federation areas of entrepreneurial (professional) activity.

To date, according to analysts, the actual number of SROs exceeds official data significantly. Many commercial SROs are being created, the activities of which negatively affect the reputation of the mechanism of self-regulatory communities.

Short-sighted customers, falling for low requirements and small cash contributions, join the ranks of such SROs. As a result, they suffer from it, covering the damage caused by many unscrupulous partners who freely entered the SRO without observing the necessary requirements [2].

There are frequent cases of dissolution of SROs after inspections, invalidation of their certificates or, even worse, the sudden disappearance of such SROs together with a full compensation fund and membership fees. One of the tools against the commercialization of SROs is the introduction of a rating system.

The possibility of an objective evaluation of a large number of self-regulatory organizations taking into consideration all the components of such evaluation is necessary for every participant of a self-regulatory process. First of all, It's necessary for the self- 
identification of current and potential members of an SRO, who should be aware of all the benefits and risks of joining an organization. This assessment will help a consumer to establish their own level of confidence to the members of such an SRO and reduce the risks of low-quality service.

\section{Materials and methods}

Self-regulation in the field of engineering research was introduced in the Russian Federation to replace engineering research licenses (licenses for engineering research activities for the construction of buildings and structures of I and II level of responsibility) on January 1, 2009. This means that in order to carry out engineering research in Russia research organizations need to join a self-regulatory organization (SRO).

Self-regulation of professional associations has already begun to be accepted by a consumer. And the possibility of an objective evaluation and rating of the activities of an SRO becomes essential to everyone as much as the possibility of evaluating the final work contractor. Nowadays, numerous cases of negligence and methods of dividing SROs into "commercial" and "correct" are widely discussed. SRO rating systems, which evaluate according to criteria and methods that, however, are not always transparent for both the customer and the evaluated entities, are being formed [3].

According to Section 6.2 of the legislative proposal on SROs, the annual assessment report must be given by the federal executive. Experts claim that "the annual report will provide the opportunity to analyze, compare and evaluate the effectiveness of selfregulation which means that legislative solutions will be more accurate and efficient [4].

\section{Results}

The authors of the article attempt to develop a theory and a methodological approach to the integrated assessment of efficiency and rating of self-regulatory organizations in the field of engineering research.

The current aim of the study is to research all indicators that can serve as the source of objective evaluation of efficiency and rating of a self-regulatory organization.

The integrated approach implies consistent consideration of qualitative and quantitative (financial and non-financial) indicators of a self-regulatory organization and determining the rating of its belonging to a particular reliability class.

Like any financial institution, an SRO should demonstrate the cost-effectiveness of operations (preservation and enhancement of entrusted funds). An SRO should cover the costs which come from the organization of mutual financial aid and accumulate resources in order to form reserves for the financial programs further development and financial stability.

As a non-profit organization which provides intensive service to a large number of participants given the moderate financial margin, an SRO should demonstrate efficiency and cost optimization while maintaining a high level and dynamics of activity indicators.

\section{Discussions}

The integrated approach to determining SRO rating consists of 3 consistent modules.

A block diagram of the integrated approach is shown in Figure 2. 


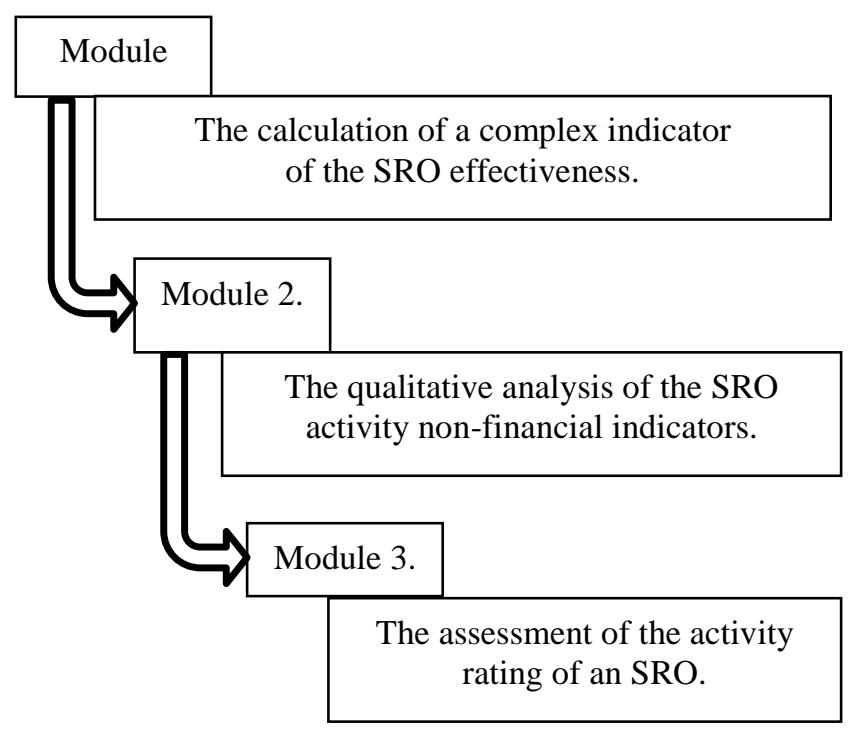

Fig. 2. The integrated approach to rating assessment and the effectiveness of an SRO.

Module 1. The calculation of an SRO activity composite indicator

Taking into consideration the studied theoretical approaches in the field of financial analysis we can conclude that "we should use several groups of indicators which correspond to the following areas of an SRO analysis in the final rating":

- Indicators of the balance dynamics;

- Indicators of cash flow;

- Indicators of financial results;

- Indicators of the compensation fund development and structure;

- Indicators of target financing and fund application;

- Indicators of property status,

- Indicators of the state of property sources,

- Indicators of financial stability and others.

To assess the SRO effectiveness we use an algorithm that includes the following steps:

1. To determine weight coefficients for each activity effectiveness indicator with the help of the expert method.

2. To calculate activity effectiveness indicators with weight coefficients.

3. To calculate the integral indicator of activity evaluation using the following formula:

$$
\mathrm{K}=\sum_{i=1}^{n} \beta i * K i
$$

$\mathrm{K}$ is a composite indicator of performance evaluation;

$\mathrm{Ki}$ is the main indicators of evaluation;

$\beta \mathrm{i}$ is weight coefficients of the $\mathrm{i}$-indicator.

The result related to the level of the integral indicator of the activity effectiveness is to be rated on a scale presented in table 1 . 
Table 1. Scale of the SRO effectiveness.

\begin{tabular}{|c|c|}
\hline Quantitative values & Qualitative ratings \\
\hline $1-1,50$ & $\begin{array}{c}\text { Financial and property independence, } \\
\text { high performance }\end{array}$ \\
\hline $0-0,99$ & $\begin{array}{c}\text { Financial and property dependence, } \\
\text { inefficient activity }\end{array}$ \\
\hline
\end{tabular}

Module 2. Qualitative analysis of SRO activity non-financial indicators

For the analysis of the intra-company situation, we select factors which determine the authority of an SRO. A survey among members of an SRO showed the following results (table 2).

Table 2. Factors which determine the authority of an SRO.

\begin{tabular}{|c|c|c|}
\hline Factors & $\mathbf{0}$ & $\mathbf{1}$ \\
\hline $\begin{array}{c}\text { 1.The presence of sufficient competence and reputation } \\
\text { 2. Transparency and openness of activities } \\
\text { associations }\end{array}$ & low & high \\
\hline $\begin{array}{c}\text { 3. Reputation in business community } \\
\text { 4. Decisiveness and independence when } \\
\text { interacting with authorities }\end{array}$ & no & yes \\
\hline $\begin{array}{c}\text { 5. Financial and property independence (based on } \\
\text { module 1) }\end{array}$ & dependant & independent \\
\hline $\begin{array}{c}\text { 6. Reputation in business community } \\
\text { 7. The number of members in the association }\end{array}$ & nelow 100 & yes \\
\hline \multicolumn{2}{c}{$\mathrm{X}\{0 ; 7\}$} \\
\hline
\end{tabular}

A quantitative number is determined. Any deviation from this number is not a positive point in the activity of an organization.

Module 3. Evaluation of SRO activity rating

Analysis of SRO websites which work transparently allowed to select the following indicators: register of members $(\max )$, the size of CF SRO per 1 member (not less than 150 thousand rubles.), admission fee, rubles ( $\mathrm{min}$ ), monthly fee, rub., factors determining the authority of an SRO (table 2).

For each indicator, the average values are calculated according to the object under study, then the formula is used to calculate a rating number.

The higher the rating number, the higher the rating of the organization:

$\mathrm{RO}$ is the rating number;

$$
\mathrm{PO}=\Sigma((\mathrm{X}-\mathrm{X} a v) / \mathrm{X} a v)^{2} \Rightarrow \max
$$

$\mathrm{X}$ is the value of the indicator;

$\mathrm{Xav}$ is the average value of the indicator.

Such average estimates make it possible to compare several SROs. 
This study allows evaluating the quantitative and qualitative indicators which affect SRO overall performance and rating. The methodical approach was tested when building the ranking of self-regulatory organizations in the field of engineering research.

\section{Conclusions}

Despite the fact that SROs occupy a key place in the system of control over entrepreneurial (professional) activities, many gaps and shortcomings are still observed in their work.

Ratings make it possible to objectively assess compliance of self-regulatory organizations with the requirements of current legislation, to control over the activities of their members, ensuring the safety of compensation funds, and are based on the analysis of dozens of indicators.

Thus, an integrated assessment allows combining a formal economic analysis in terms of SRO effectiveness and its subjective assessment from the point of view of functioning evaluation and obtain an integral estimate. When deciding to join the SRO, respondents rely on the presence of sufficient competence and reputation, transparency and openness of the association activities.

The proposed approach can be used by self-regulatory organizations for selfidentification of members and by consumers for establishing their own level of confidence to members of an SRO, professional community and authorities.

\section{References}

1. L.S. Barinova, Self-regulation in the construction industry (2010)

2. M.V. Viktorov, Self-regulation as a sustainable factor of the construction industry development (2016)

3. A.A. Zel'vinskaya, «Publ. Admin. Iss. » J. 3, 7-30 (2016)

4. 4 A. Bandura, Ann. Revi. Psy., 52(1), 1-26. (2001). 